\title{
Prevalence of symptomatic and silent stress-induced perfusion defects in diabetic patients with suspected coronary artery disease referred for myocardial perfusion scintigraphy
}

\author{
John O. Prior1, David Monbaron², Melanie Koehli1, 2, Maria-Lucia Calcagni¹, Juan Ruiz², Angelika Bischof Delaloye1 \\ 1 Division of Nuclear Medicine, Centre Hospitalier Universitaire Vaudois (CHUV University Hospital), Lausanne, Switzerland \\ 2 Division of Endocrinology, Diabetology and Metabolism, Centre Hospitalier Universitaire Vaudois (CHUV University Hospital), Lausanne, \\ Switzerland
}

Received: 18 February 2004 / Accepted: 28 April 2004 / Published online: 10 August 2004

(C) Springer-Verlag 2004

\begin{abstract}
Purpose: Silent myocardial ischaemia—as evaluated by stress-induced perfusion defects on myocardial perfusion scintigraphy (MPS) in patients without a history of chest pain-is frequent in diabetes and is associated with increased rates of cardiovascular events. Its prevalence has been determined in asymptomatic diabetic patients, but remains largely unknown in diabetic patients with suspected coronary artery disease (CAD) in the clinical setting. In this study we therefore sought (a) to determine the prevalence of symptomatic and silent perfusion defects in diabetic patients with suspected CAD and (b) to characterise the eventual predictors of abnormal perfusion. Methods: The patient population comprised 133 consecutive diabetic patients with suspected CAD who had been referred for MPS. Studies were performed with exercise $(41 \%)$ or pharmacological stress testing (1-day protocol, 99mTc-sestamibi, ${ }^{201} \mathrm{Tl}$ or both). We used semi-quantitative analysis (20-segment polar maps) to derive the summed stress score (SSS) and the summed difference score (SDS). Results: Abnormal MPS (SSS $\geq 4$ ) was observed in 49 $(37 \%)$ patients $(\mathrm{SSS}=4.9 \pm 8.4, \mathrm{SDS}=2.4 \pm 4.7)$, reversible perfusion defects $(\mathrm{SDS} \geq 2)$ in $40 \quad(30 \%)$ patients [SSS $=13.3 \pm 10.9 ; \mathrm{SDS}=8.0 \pm 5.6 ; 20 \%$ moderate to severe (SDS>4), 7\% multivessel] and fixed defects in $21(16 \%)$ patients. Results were comparable between patients with and patients without a history of chest pain. Of 75 patients without a history of chest pain, $23(31 \%, 95 \%$

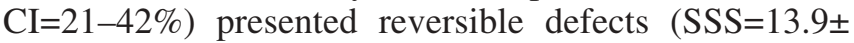
11.3; SDS=7.4 \pm 1.2 ), indicative of silent ischaemia. Reversible defects were associated with inducible ST segment depression during MPS stress [odds ratio
\end{abstract}

John O. Prior (-)

Division of Nuclear Medicine,

Centre Hospitalier Universitaire Vaudois

(CHUV University Hospital),

1011 Lausanne, Switzerland

e-mail: john.prior@chuv.hospvd.ch

Tel.: +41-21-3144347, Fax: +41-21-3144349
$(\mathrm{OR})=3.2, p<0.01)$. Fixed defects were associated with erectile dysfunction in males $(\mathrm{OR}=3.7, p=0.02)$ and lower aspirin use $(\mathrm{OR}=0.25, p=0.02)$.

Conclusion: Silent stress-induced perfusion defects occurred in $31 \%$ of the patients, a rate similar to that in patients with a history of chest pain. MPS could identify these patients with a potentially increased risk of cardiovascular events.

Keywords: Myocardial perfusion scintigraphy - Diabetes - Myocardial ischaemia - Silent myocardial ischaemia - Single photon emission computed tomography

Eur J Nucl Med Mol Imaging (2005) 32:60-69

DOI 10.1007/s00259-004-1591-0

\section{Introduction}

The prevalence of diabetes mellitus has continued to grow over the past decade, and the disease has now reached epidemic proportions. Worldwide, it affects roughly 150 million individuals and this number is expected to double by the year 2025 [1]. Diabetes increases the risk of coronary artery disease (CAD) by a factor of 2-4 [2]. Moreover, CAD accounts for as many as $75 \%$ of diabetes-related deaths [2]. Myocardial ischaemia is a major complication in the course of diabetes [3], and $25 \%$ of patients with type 2 diabetes already have CAD at the time of diagnosis [4]. Thus, the early detection of CAD in diabetic patients has become a priority, and guidelines have been developed to define a high-risk profile of diabetic patients who might benefit from routine cardiac screening $[5,6]$. This screening can be done using myocardial perfusion scintigraphy (MPS) [7], which has been shown to be of value for diagnosing significant CAD in diabetic individuals and for risk stratification and management $[8,9]$. It is known that chest pain 
symptoms are more frequently blunted in diabetic than in non-diabetic patients, possibly delaying referral of patients with silent ischaemia $[10,11]$. Silent myocardial ischaemia can be a terminal event at its first presentation, and has a potentially worse outcome than symptomatic ischaemia [12]. An ongoing multicentre trial on the detection of ischaemia in asymptomatic diabetic patients (DIAD) [13] will help determine its prevalence and to establish evidence-based screening criteria. Meanwhile, diabetic patients without CAD are commonly referred for MPS and the prevalence of silent perfusion defects in the clinical setting remains largely undefined.

We therefore sought (1) to determine the prevalence of symptomatic and silent perfusion defects in consecutive diabetic patients without $\mathrm{CAD}$ who were referred for MPS, potentially defining a group of patients at higher risk of cardiovascular events, and (2) to characterise the eventual predictors of abnormal perfusion.

\section{Materials and methods}

Patient population

We considered all consecutive diabetic patients $(n=210)$ referred for MPS in our Nuclear Medicine Division from June 1997 to July 2002 and excluded 54 patients with known CAD (including recent myocardial infarction or unstable angina), 11 patients who did not give their consent to participation and 12 patients whose complete medical record and MPS could not be fully retrieved for evaluation. Thus, the study included 133 consecutive diabetic patients referred for MPS with suspected CAD. There were slightly more referrals from physicians outside the hospital (55\%). All studies were performed in compliance with standard institutional practice guidelines. The local ethics committee of the University of Lausanne Medical School approved this study. The clinical studies performed in this report comply with the current Swiss laws.

\section{Clinical characteristics}

The diagnosis of diabetes was established by the referring physician prior to MPS and confirmed by patient history or the use of medication such as insulin or oral hypoglycaemic agents. Hypertension was identified by resting blood pressure values $\geq 140 / 80 \mathrm{mmHg}$ or by the use of anti-hypertensive therapy. Dyslipidaemia was established by a total cholesterol value of $\geq 5.2 \mathrm{mmol} / \mathrm{l}$ or the use of lipid-lowering agents. Obesity was defined for body mass index $(\mathrm{BMI}) \geq 30 \mathrm{~kg} / \mathrm{m}^{2}$. Smoking information was obtained by patient history. The number of major cardiovascular risk factors (hypertension, dyslipidaemia, smoking, obesity and diabetes) was also reported. Chest pain was assessed according to the previously established Rose-WHO angina questionnaire [14]. Typical angina pectoris was described as pain or chest discomfort localised behind the sternum, left chest wall or left arm when exercising, with a need to slow down or stop and disappearance of the initial chest sensation within $10 \mathrm{~min}$. Atypical chest pain was a defined by a positive answer to the question, "Have you ever had any pain or chest discomfort in your chest?" [14]. Other clinical parameters such as diabetes complications (retinopathy, peripheral occlusive disease, nephropathy/microalbumin- uria, congestive heart failure and erectile dysfunction) and drug history were obtained by patient history, medical records and referring physician contact by letter or phone.

\section{SPECT MPS protocols}

We performed a conventional 1-day protocol using: (1) dual-isotope ${ }^{201} \mathrm{Tl}(111 \mathrm{MBq})$ for rest and $99 \mathrm{mTc}-m e t h o x y i s o b u t y l i s o n i t r i l e$ (MIBI/sestamibi, $925 \mathrm{MBq}$ ) for stress in 41\% (54/133), (2) singleisotope ${ }^{201} \mathrm{Tl}(111 \mathrm{MBq})$ in $22 \%(30 / 133)$ and (3) $99 \mathrm{mTc}-\mathrm{MIBI}$ (370 MBq for stress, $925 \mathrm{MBq}$ for rest) in 37\% [49/133, essentially in obese patients (BMI $\left.\geq 30 \mathrm{~kg} / \mathrm{m}^{2}\right)$ ]. We used a dual-head gamma camera (Siemens E.-Cam; Siemens, Erlangen, Germany) with low-energy, high-resolution parallel-hole collimators to acquire $32 \times 40$-s projections along a $180^{\circ}$, non-circular orbit with heads at $90^{\circ}$ from another. Standard energy settings were used [ ${ }^{99 \mathrm{~m} T c}, 20 \%$ energy window centered at $140 \mathrm{keV}(20 \%, 140 \mathrm{keV}) ;{ }^{201} \mathrm{Tl},(20 \%$; $70 \mathrm{keV})$ and $(14 \% ; 166 \mathrm{keV}))$. The $64 \times 64$-pixel summed images were filtered with a fifth-order Butterworth filter with a cut-off frequency of 0.40 cycles/pixel. Resting images were acquired 15-30 min after rest ${ }^{201} \mathrm{Tl}$ or $99 \mathrm{~m} \mathrm{Tc}-\mathrm{MIBI}$ injection and stress images started 30-45 min after stress ${ }^{99 \mathrm{~m} T c-M I B I}$ injection.

Exercise and pharmacological stress protocols

Exercise testing was performed with a bicycle ergometer using multiple 2-min steps (25- or $30-\mathrm{W}$ increments) to reach an adequate exercise level, as defined by heart rate $\geq 85 \%$ of maximum predicted for age $(=220-$ age). The radionuclide tracer was injected at peak exercise, which was maintained for at least 1 and preferably for $2 \mathrm{~min}$. In 59\% (79/133) of the patients, exercise was impossible or an adequate exercise level was not achieved, and pharmacological stress testing with standard dose 4-min dipyridamole infusion $(0.56 \mathrm{mg} / \mathrm{kg}$ Persantin; Boehringer Ingelheim International $\mathrm{GmbH}$ ) was used, supplemented in some cases by isometric handgrip or low-dose bicycle stress $(25-60 \mathrm{~W})$. The reasons for decreased exercise capacity included obesity, peripheral vascular disease, sensory or motor neuropathy, abnormal orthopaedic status and deconditioning. Tracer injection was performed 3 min after the end of dipyridamole infusion. At least $1 \mathrm{~h}$ separated stress and rest studies ( $4 \mathrm{~h}$ in the case of single injection of ${ }^{201} \mathrm{Tl}$ ). Standard 12-lead ECG and blood pressure were recorded at rest and every 2 min during stress and recovery. The exercise ECG was considered positive for ischaemia in the presence of horizontal or downsloping ST segment depression $\geq 0.1 \mathrm{mV}$ measured $80 \mathrm{~ms}$ after the J-point or $\geq 0.2 \mathrm{mV}$ in the case of upsloping ST segment depression. No serious cardiovascular side-effect was reported in response to pharmacological stress testing.

\section{MPS interpretation}

We performed visual analysis of rest and stress images displayed on short-axis, horizontal-long axis and vertical-long axis views, and semi-quantitative analysis of polar maps using the Emory Cardiac Toolbox software (Emory University, Atlanta, GA, USA). Using a 20-segment nomenclature, two expert readers (M.L.C., A.B.D.) unaware of the patient's clinical history at the time of evaluation interpreted each segment on a five-point scale of count activity $(0$, normal; 1 , equivocal; 2 , moderate reduction; 3 , severe reduction; and 4, absent activity) [15]. Global indices of perfusion 
were obtained by adding the score of the 20 segments at stress [summed stress score (SSS)] and at rest [summed rest score (SRS)] and by calculating their difference [summed difference score $(\mathrm{SDS})=$ SSS-SRS], which represents both extent and severity of perfusion abnormalities [16]. MPS was classified as normal (SSS $<4)$, mildly abnormal ( $\mathrm{SSS}=4-8$ ), moderately abnormal (SSS=9-13) or severely abnormal (SSS $>13$ ) [17]. Reversible perfusion defects, as defined by $\mathrm{SDS} \geq 2$, were graded as mild ( $\mathrm{SDS}=2-4)$ or moderate to severe ( $\mathrm{SDS}>4$ ). Fixed defects were considered present if $\mathrm{SRS} \geq 2$ and $\mathrm{SDS}<2$. Myocardial segments were associated with coronary artery territories (left anterior descending, left circumflex and right coronary arteries) [15], and a multivessel disease pattern was considered present if $\mathrm{SSS} \geq 4$ in two different territories.

Statistical analysis

To characterise the prevalence of silent ischaemia, patients were grouped according to the history of chest pain prior to MPS. Comparisons between groups were performed with the Wilcoxon ranksum test for continuous variables and with Pearson's $\chi^{2}$ test or Fisher's exact test (when appropriate) for categorical data. In the text and tables, values were reported as mean $\pm \mathrm{SD}$, and we used 5 th percentile to 95 th percentile confidence intervals (CI). Reversible and fixed MPS perfusion defects were analysed using multiple logistic regression analysis. Because a substantial number of ECGs could not be assessed, stress-induced ST segment depression was represented on an ordinal scale in logistic regression (0, no ST segment depression; 1 , ST segment non-assessable for depression; 2, ST segment depression). We carried out statistical analyses with Stata 8.2 (Stata Corporation, College Station, TX, USA) and $p$ values $<0.05$ were considered statistically significant.

\section{Results}

\section{Patient characteristics}

The mean age of the 133 diabetic patients was $62 \pm$ 9 years (range $32-81$ years) and $44 \%$ were women. Forty-four percent (58/133) of the MPS studies were requested for chest pain investigation [23\% (31/133) for typical angina pectoris], 39\% (52/133) for suspicion or exclusion of ischaemia without symptoms of chest pain (such as recent onset of dyspnoea, malaise, abnormal exercise testing or echocardiography, duration of diabetes, complications, or constellation of cardiovascular risk factors) and $17 \%$ (23/133) for pre-operative risk assessment. Overall, $56 \%$ of patients had no history of chest pain and $44 \%$ had experienced chest pain (23\% with angina pectoris, $20 \%$ with atypical chest pain), with slightly more women in the chest pain group (Table 1). In the group without chest pain, trends were noted towards more frequent use of insulin, more retinopathy and more peripheral occlusive disease. Triglyceride levels were higher in the chest pain group, but this difference was no longer significant after removing one outlier $(10.45 \mathrm{mmol} / \mathrm{l})$ in the chest pain group. There was no difference in drug treatment between the groups (all $p>0.33$ ). Hypertension was treated medically in $85 \%$ (95/112) of the hypertensive patients. Fifty-two percent $(45 / 86)$ of the patients with a high cholesterol level used lipid-lowering medication and 41\% (55/133) were taking aspirin daily. There was a higher referral rate for preoperative risk assessment in patients without chest pain [25\% (19/133) vs 7\% (4/133), $p<0.01]$.

\section{Reversible and fixed MPS perfusion defects}

Results of MPS (listed in Table 2) were abnormal in $37 \%$ (49/133, CI 29-46\%) of the patients, without differences between the groups with or without a history of chest pain. Using SSS, we further characterised abnormal MPS into mildly abnormal (17\%), moderately abnormal $(10 \%)$ and severely abnormal (10\% CI 5-16\%). Using SDS, we observed reversible perfusion defects in $30 \%$ (40/133, CI 22-39\%) of the patients, which were moderate to severe in $20 \%$ and multivessel in $7 \%$. The prevalence of silent, reversible perfusion defects in patients without chest pain, indicative of silent ischaemia, was $31 \%(23 / 75$, CI $21-42 \%)$, with an $\mathrm{SSS}=13.9 \pm 11.3$ and an SDS=7.4 \pm 1.2 ; the defects were mostly confined to a single vessel. We carried out a separate analysis (data not shown) between patients with typical angina pectoris $(n=31)$ and patients with atypical chest pain $(n=27)$ and found no difference in respect of perfusion defects ( $p>0.14$ for all comparisons), allowing us to consider them as a single group for the purpose of analysis. Fixed defects were observed in 16\% (CI 10-23\%) of patients. As demonstrated in Table 3, gender, age and duration of diabetes were similar in the presence or absence of reversible defects (all $p>0.61$ ). Similarly, patients with and patients without fixed perfusion defects did not differ with regard to age, gender, history of chest pain or diabetes duration (all $p>0.28$ ). All fixed perfusion defects were limited to a single territory.

\section{Stress-induced ST segment depression and chest pain during MPS stress testing}

The ECG was assessed for ischaemic changes in $86 \%$ $(114 / 133)$ of the patients and could not be assessed in the remaining $14 \%$ because of pre-existing ST abnormalities at rest [due to conduction abnormalities (such as left bundle branch block or pre-excitation), left ventricular hypertrophy and digoxin therapy]. During the stress part of MPS, ST segment depression was observed in $20 \%$ (23/114) of assessable ECGs and did not depend on chest pain history (Table 2). It is of note that ST segment depression was observed more often in patients who underwent physical exercise than in those who received pharmacological infusion [31\% (15/49) vs $12 \%(8 / 65)$, $p=0.02]$. Stress-induced chest pain during MPS was rare [10\% (14/133), Table 2; atypical, $n=4$; typical angina, 
Table 1. Basic population characteristics

\begin{tabular}{|c|c|c|c|c|}
\hline Variable $[$ mean $\pm \mathrm{SD}$ or $n(\%)]$ & No chest pain $(n=75)$ & Chest pain $(n=58)$ & $p$ value & Total $(n=133)$ \\
\hline Age \pm SD $($ years $)$ & $61 \pm 10$ & $63 \pm 9$ & 0.17 & $62 \pm 9$ \\
\hline Body mass index $\left(\mathrm{kg} / \mathrm{m}^{2}\right)$ & $32.9 \pm 7.0$ & $32.3 \pm 6.5$ & 0.65 & $32.6 \pm 6.5$ \\
\hline No. of women $(\%)$ & $27(36 \%)$ & $31(43 \%)$ & 0.04 & $58(44 \%)$ \\
\hline Pharmacological stress $(\%)$ & $47(63 \%)$ & $32(55 \%)$ & 0.38 & $79(59 \%)$ \\
\hline Non-assessable ST segment on ECG (\%) & $11(15 \%)$ & $8(14 \%)$ & 0.89 & $19(14 \%)$ \\
\hline \multicolumn{5}{|l|}{ Diabetes } \\
\hline Duration (years) & $9.7 \pm 9.0$ & $10.5 \pm 10.0$ & 0.64 & $10.0 \pm 9.4$ \\
\hline Type 1 diabetes (\%) & $4(5 \%)$ & $2(3 \%)$ & 0.70 & $6(5 \%)$ \\
\hline \multicolumn{5}{|l|}{ Treatment } \\
\hline Insulin total $(\%)$ & $38(51 \%)$ & $20(34 \%)$ & 0.06 & $58(43 \%)$ \\
\hline Insulin only $(\%)$ & $25(33 \%)$ & $13(22 \%)$ & 0.18 & $38(29 \%)$ \\
\hline Insulin + oral hypoglycaemic (\%) & $13(17 \%)$ & $7(12 \%)$ & 0.47 & $20(15 \%)$ \\
\hline Oral hypoglycaemic only (\%) & $39(52 \%)$ & $32(55 \%)$ & 0.72 & $71(53 \%)$ \\
\hline $\operatorname{Diet}(\%)$ & $11(15 \%)$ & $13(22 \%)$ & 0.27 & $24(18 \%)$ \\
\hline Glycosylated haemoglobin $\mathrm{HbA}_{1 \mathrm{c}}(\%)$ & $8.1 \pm 2.5$ & $7.7 \pm 2$ & 0.44 & $7.9 \pm 2.3$ \\
\hline \multicolumn{5}{|l|}{ Diabetic complications } \\
\hline Retinopathy $(\%)$ & $21(28 \%)$ & $8(14 \%)$ & 0.06 & $29(22 \%)$ \\
\hline Peripheral occlusive disease $(\%)$ & $17(23 \%)$ & $6(10 \%)$ & 0.07 & $23(17 \%)$ \\
\hline Nephropathy/microalbuminuria (\%) & $19(25 \%)$ & $14(24 \%)$ & 0.87 & $33(25 \%)$ \\
\hline Chronic haemodialysis $(\%)$ & $3(4 \%)$ & $2(4 \%)$ & 0.87 & $5(4 \%)$ \\
\hline Peripheral neuropathy (\%) & $31(41 \%)$ & $18(31 \%)$ & 0.28 & $49(37 \%)$ \\
\hline Erectile dysfunction (\% males) & $17(35 \%)$ & $9(33 \%)$ & 0.86 & $26(35 \%)$ \\
\hline Congestive heart failure (\%) & $9(12 \%)$ & $9(15 \%)$ & 0.61 & $18(14 \%)$ \\
\hline \multicolumn{5}{|l|}{ Laboratory values } \\
\hline Total cholesterol (mmol/l) & $5.6 \pm 2$ & $5.8 \pm 1.4$ & 0.17 & $5.7 \pm 1.7$ \\
\hline LDL cholesterol (mmol/l) & $3.3 \pm 0.9$ & $3.4 \pm 1.0$ & 0.67 & $3.3 \pm 0.9$ \\
\hline HDL cholesterol (mmol/l) & $1.1 \pm 0.3$ & $1.2 \pm 0.3$ & 0.76 & $1.1 \pm 0.3$ \\
\hline Ratio total cholesterol/HDL (1) & $5.1 \pm 1.9$ & $5.4 \pm 2.2$ & 0.68 & $5.2 \pm 2.0$ \\
\hline Triglycerides $(\mathrm{mmol} / \mathrm{l})$ & $2.2 \pm 1.0$ & $3.1 \pm 2.2$ & 0.04 & $2.6 \pm 1.7$ \\
\hline \multicolumn{5}{|l|}{ Blood pressure } \\
\hline Systolic blood pressure (mmHg) & $143 \pm 18$ & $148 \pm 20$ & 0.21 & $145 \pm 19$ \\
\hline Diastolic blood pressure (mmHg) & $85 \pm 11$ & $84 \pm 11$ & 0.47 & $85 \pm 11$ \\
\hline \multicolumn{5}{|l|}{ Cardiovascular risk factors } \\
\hline Hypertension (\%) & $65(86 \%)$ & $47(81 \%)$ & 0.47 & $112(84 \%)$ \\
\hline Dyslipidaemia $(\%)$ & $49(65 \%)$ & $37(64 \%)$ & 0.85 & $86(65 \%)$ \\
\hline Obesity $\left(\mathrm{BMI} \geq 30 \mathrm{~kg} / \mathrm{m}^{2}\right)(\%)$ & $54(72 \%)$ & $40(68 \%)$ & 0.70 & $94(71 \%)$ \\
\hline Smoking $(\%)$ & $24(32 \%)$ & $11(19 \%)$ & 0.11 & $35(26 \%)$ \\
\hline No. of risk factors & $3.9 \pm 1.3$ & $3.5 \pm 1.0$ & 0.08 & $3.7 \pm 1.2$ \\
\hline \multicolumn{5}{|l|}{ Treatment } \\
\hline Aspirin $(\%)$ & $31(41 \%)$ & $24(41 \%)$ & 0.99 & $55(41 \%)$ \\
\hline$\beta$-Blockers $(\%)$ & $11(15 \%)$ & $11(19 \%)$ & 0.64 & $22(17 \%)$ \\
\hline ACE inhibitors (\%) & $36(48 \%)$ & $25(43 \%)$ & 0.60 & $61(46 \%)$ \\
\hline Calcium antagonists $(\%)$ & $18(24 \%)$ & $16(28 \%)$ & 0.69 & $34(26 \%)$ \\
\hline Diuretics $(\%)$ & $25(33 \%)$ & $19(33 \%)$ & 0.94 & $44(33 \%)$ \\
\hline Statins and/or fibrates (\%) & $28(37 \%)$ & $17(29 \%)$ & 0.33 & $45(34 \%)$ \\
\hline
\end{tabular}

$n=10]$ and was independent of chest pain history or the type of stress $(p=0.25)$. We observed the first episode of chest pain during MPS stress testing in five patients who had no prior history of chest pain, of whom four had reversible MPS perfusion defects.

\section{Predictors of reversible and fixed defects on MPS}

Reversible defects on MPS (Table 3) were more frequently observed in combination with stress-induced ST segment depression when the ECG could be assessed 
Table 2. Results of MPS according to chest pain history

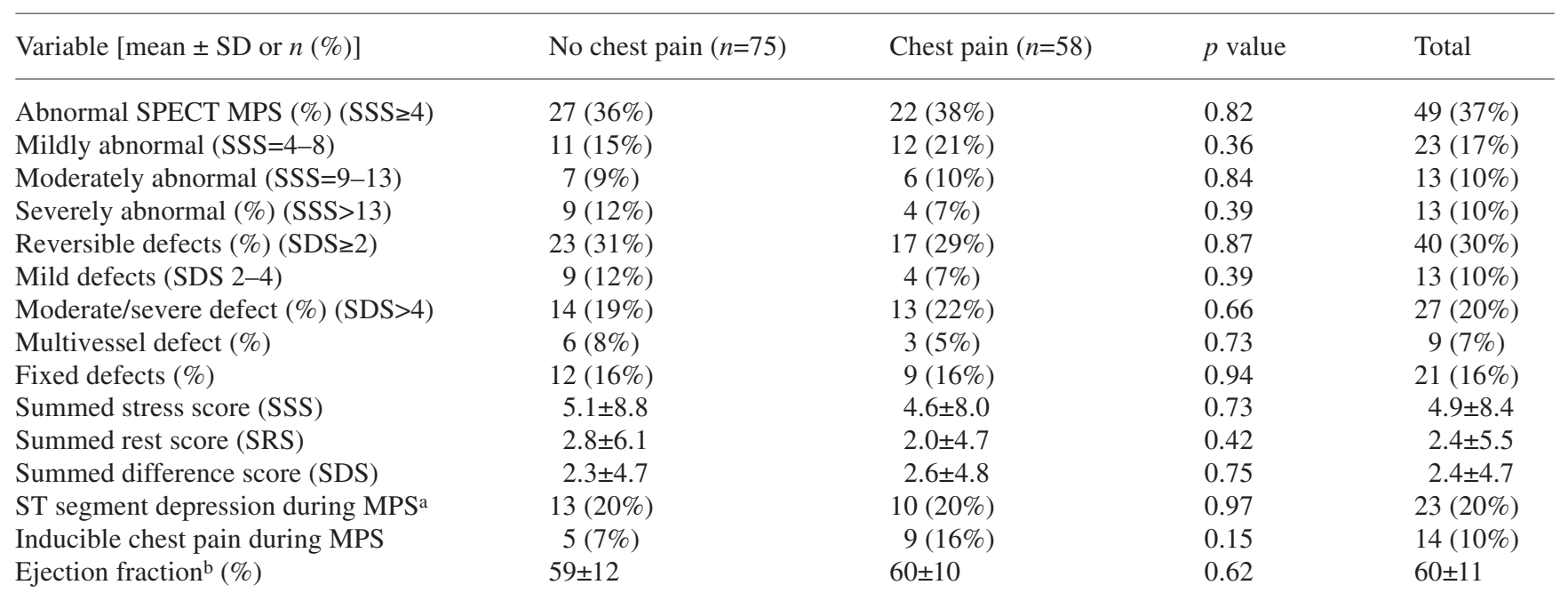

SSS, summed stress score; SDS, summed difference score; SRS, summed rest score.

${ }^{a}$ ECG assessed in 114 patients (19 patients with pre-existing ST segment or conduction abnormalities).

${ }^{\mathrm{b}}$ Assessed in a subpopulation of 87 patients ( $n=39$ with chest pain).

Table 3. Results of MPS according to presence of reversible defects

\begin{tabular}{|c|c|c|c|c|}
\hline Variable $[$ mean $\pm \mathrm{SD}$ or $n(\%)]$ & $\begin{array}{l}\text { No reversible defect } \\
(n=93)\end{array}$ & $\begin{array}{l}\text { Reversible defect } \\
(n=40)\end{array}$ & $p$ & $\begin{array}{l}\text { Total } \\
(n=133)\end{array}$ \\
\hline Age (years) & $61 \pm 10$ & $62 \pm 8$ & 0.71 & $62 \pm 9$ \\
\hline Gender: no. of men (\%) & $51(55 \%)$ & $24(60 \%)$ & 0.58 & $75(56 \%)$ \\
\hline Diabetes duration (years) & $10.3 \pm 9.1$ & $9.4 \pm 10.2$ & 0.61 & $10.0 \pm 9.4$ \\
\hline Diabetes treated with insulin (\%) & $44(47 \%)$ & $14(35 \%)$ & 0.19 & $58(44 \%)$ \\
\hline Pharmacological stress (\%) & $59(63 \%)$ & $20(50 \%)$ & 0.15 & $79(59 \%)$ \\
\hline Chest pain before MPS (\%) & $41(44 \%)$ & $17(43 \%)$ & 0.87 & $58(44 \%)$ \\
\hline Summed stress score (SSS) & $1.2 \pm 2.7$ & $13.3 \pm 10.9$ & $<0.001$ & $4.9 \pm 8.4$ \\
\hline Summed rest score (SRS) & $1.2 \pm 2.6$ & $5.4 \pm 8.7$ & $<0.001$ & $2.4 \pm 5.5$ \\
\hline Summed difference score (SDS) & $0.06 \pm 0.25$ & $8.0 \pm 5.6$ & $<0.001$ & $2.4 \pm 4.7$ \\
\hline ST segment depression during MPSa (\%) & $8(10 \%)$ & $15(50 \%)$ & $<0.001$ & $23(20 \%)$ \\
\hline ECG non-assessable for ST segment depression & $9(10 \%)$ & $10(25 \%)$ & 0.03 & $19(14 \%)$ \\
\hline Inducible chest pain during MPS (\%) & $9(10 \%)$ & $5(12 \%)$ & 0.76 & $14(11 \%)$ \\
\hline Ejection fraction ${ }^{\mathrm{b}}(\%)$ & $62 \pm 11$ & $55 \pm 11$ & 0.01 & $60 \pm 12$ \\
\hline Hypertension $(\%)$ & $74(80 \%)$ & $38(95 \%)$ & 0.04 & $112(84 \%)$ \\
\hline Nephropathy/microalbuminuria (\%) & $24(26 \%)$ & $9(23 \%)$ & 0.83 & $33(25 \%)$ \\
\hline Peripheral neuropathy $(\%)$ & $36(39 \%)$ & $13(33 \%)$ & 0.56 & $49(37 \%)$ \\
\hline Aspirin $(\%)$ & $32(34 \%)$ & $23(58 \%)$ & 0.02 & $55(41 \%)$ \\
\hline ACE inhibitors (\%) & $37(40 \%)$ & $24(60 \%)$ & 0.04 & $61(46 \%)$ \\
\hline
\end{tabular}

SSS, summed stress score; SDS, summed difference score; SRS, summed rest score.

(50\% vs $10 \%, p<0.001)$, with hypertension or with the use of aspirin or angiotensin converting enzyme (ACE) inhibitors. On univariate analysis (Table 4), there was an association between reversible defects and inducible ST segment depression during MPS $(p<0.001)$, non-assessable ST segment $(p=0.02)$, hypertension $(p=0.02)$ and
${ }^{a}$ ECG assessed in 114 patients (19 patients with pre-existing ST segment or conduction abnormalities).

b Assessed in a subpopulation of 87 patients ( $n=23$ with reversible defects).

the use of aspirin $(p=0.01)$ or ACE inhibitors $(p=0.03)$. There was no association with other variables such as age, gender, duration of diabetes, type of stress and chest pain history. On multivariate analysis, the only independent predictor of reversible defects was stress-induced ST segment depression (OR 3.2 \pm 0.9 , CI $1.9-5.4$ 
Table 4. Univariate and multivariate analysis of reversible and fixed perfusion defects on MPS

\begin{tabular}{|c|c|c|c|c|}
\hline \multirow[t]{3}{*}{ Variable } & \multicolumn{4}{|l|}{ Perfusion defects } \\
\hline & \multicolumn{2}{|l|}{ Univariate analysis } & \multicolumn{2}{|l|}{ Multivariate analysis } \\
\hline & $\begin{array}{l}\text { Reversible }(n=40) \\
r(p)\end{array}$ & $\begin{array}{l}\text { Fixed }(n=21), \\
r(p)\end{array}$ & $\begin{array}{l}\text { Reversible }(n=40) \\
\text { OR }(p)\end{array}$ & $\begin{array}{l}\text { Fixed }(n=21), \\
\text { OR }(p)\end{array}$ \\
\hline Age & $0.03(0.71)$ & $0.10(0.27)$ & $-(0.96)$ & $-(0.19)$ \\
\hline Gender & $0.05(0.59)$ & $0.01(0.99)$ & $-(0.44)$ & $-(0.34)$ \\
\hline Diabetes duration & $-0.05(0.52)$ & $0.01(0.90)$ & $-(0.76)$ & $-(0.76)$ \\
\hline Insulin treatment & $-0.11(0.19)$ & $-0.04(0.64)$ & $-(0.39)$ & $-(0.39)$ \\
\hline Oral hypoglycaemic treatment & $0.15(0.08)$ & $-0.01(0.90)$ & $-(0.24)$ & $-(0.83)$ \\
\hline Retinopathy & $-0.07(0.43)$ & $-0.01(0.99)$ & $-(0.76)$ & $-(0.92)$ \\
\hline Vascular occlusive disease & $-0.04(0.65)$ & $0.01(0.99)$ & $-(0.78)$ & $-(0.82)$ \\
\hline Erectile dysfunction & $-0.20(0.09)$ & $0.17(0.04)$ & $-(0.72)$ & $3.7(0.02)$ \\
\hline Peripheral neuropathy & $-0.06(0.50)$ & $-0.05(0.54)$ & $-(0.45)$ & $-(0.83)$ \\
\hline Hypertension & $0.19(0.02)$ & $-0.02(0.82)$ & $4.1(0.08)$ & $-(0.87)$ \\
\hline No. of risk factors & $0.08(0.33)$ & $-0.07(0.44)$ & $-(0.78)$ & $-(0.22)$ \\
\hline Chest pain history before MPS & $-0.01(0.87)$ & $-0.04(0.64)$ & $-(0.96)$ & $-(0.32)$ \\
\hline Chest pain during MPS & $0.05(0.54)$ & $0.07(0.44)$ & $-(0.85)$ & $-(0.39)$ \\
\hline ST segment depression during MPS & $0.43(0.001)$ & $-0.08(0.34)$ & $3.2(<0.01)$ & $-(0.68)$ \\
\hline ECG: ST segment non-assessable & $0.20(0.02)$ & $0.04(0.64)$ & $-(0.36)$ & $-(0.67)$ \\
\hline Aspirin & $0.22(0.01)$ & $-0.20(0.02)$ & $2.1(0.08)$ & $0.25(0.02)$ \\
\hline ACE inhibitors & $0.19(0.03)$ & $-0.07(0.44)$ & $-(0.40)$ & $-(0.46)$ \\
\hline
\end{tabular}

$r$ Pearson's correlation coefficient; $O R$ odds ratio.

$p<0.001)$. For fixed defects, univariate analysis unveiled an association with erectile dysfunction in males $(r=0.17, p=0.04)$ and use of aspirin $(r=-0.22, p=0.01)$, which both remained significant on multivariate analysis (erectile dysfunction: OR 3.7 \pm 2.0 , CI $1.3-10.8, p=0.02$; use of aspirin: OR $0.25 \pm 0.15$, CI $0.08-0.81, p=0.02$; note that $\mathrm{OR}<1$ corresponds to a lower likelihood of fixed defects).

\section{Discussion}

In our population of 133 diabetic patients with suspected CAD referred for MPS, we found a high prevalence of abnormal MPS (37\%), with $30 \%$ of patients having reversible defects known to be associated with an increased likelihood of cardiovascular events. Patients without a history of chest pain - at risk for silent ischaemia - had a similar prevalence of reversible and fixed defects as was observed in patients with chest pain. Reversible perfusion defects were independently predicted by stress-induced ST segment depression and fixed defects were associated with erectile dysfunction and lower aspirin use.

\section{Population characteristics}

The fact that a substantial proportion of patients were unable to achieve maximal physical exercise during
MPS was related to limited exercise potential, as is frequently observed in diabetic populations. The high rate of patients without chest pain referred for pre-operative risk assessment was most likely due to a selection bias (patients with chest pain would normally undergo exercise testing or stress echocardiography before MPS referral). The absence of a predictive value of cardiovascular risk factors for reversible defects may have been related to a reduction in discriminating power in the presence of a high prevalence, as reported previously in diabetic patients $[10,11,18]$. There was no association of the different clinical and laboratory values or drug therapy regimens with the chest pain history. Diabetes was well controlled in less than half of the patients $(42 \%)$, as defined by glycosylated haemoglobin HbA1c levels $\leq 7.0 \%$. It is of note that diabetic patients with good control did not differ from patients with glycosylated haemoglobin $\mathrm{HbA}_{1 \mathrm{c}}$ levels $>7.0 \%$ with respect to cardiovascular risk factors, lipid profile, SSS, SDS or prevalence of reversible and fixed defects. Finally, both chest pain groups had comparable left ventricular function [as measured by post-stress ejection fraction during gated SPECT at MPS in a subset of the population (87/133 or $65 \%)]$.

\section{Reversible and fixed defects on MPS}

We found a high prevalence of abnormal MPS (37\%, CI $29-46 \%$ ) in our study. It was, however, lower than the 
prevalence found in two earlier studies of diabetic patients referred for MPS (58\% in the study by Vanzetto et al. [19] for patients at risk for $\mathrm{CAD}$, and $48 \%$ in the study by Giri et al. [9] for patients at risk for/with CAD). Compared with these reports, we found a similar prevalence of reversible defects $(30 \%$, CI $22-39 \%$ vs $37 \%$ [19] and 29\% [9]) and fewer fixed defects (16\%, CI $10-23 \%$ vs 34\% [19] and 29\% [9]). These differences might be explained by the inclusion of a substantial fraction of patients with prior myocardial infarction in these earlier studies (25\% [19] and 13\% [9]). Unfortunately, neither study reported any prevalence of silent ischaemia. In the literature, most studies of silent ischaemia in diabetes as assessed by MPS were performed to investigate screening criteria in asymptomatic patients with cardiovascular risk factors, but without known or suspected CAD [13, 20, 21, 22]. Compared to our patients with suspicion of CAD, these studies reported lower rates of abnormal MPS (25-28\%) and silent ischaemia (15-26\%), most likely owing to a lower pre-test likelihood of CAD (no CAD suspicion, fewer cardiovascular risk factors) and a lesser severity of diabetes (fewer patients with insulin).

Of special interest, preliminary results from the ongoing prognostic DIAD study in 502 asymptomatic diabetic patients without known or suspected CAD showed a prevalence of $27 \%$ for abnormal MPS, with a prevalence of $18 \%$ for reversible defects, $3 \%$ for fixed defects and $2 \%$ for mixed defects. Compared with our study, the lower prevalence of silent ischaemia in DIAD (20\%) may be explained by differences in population, as our patients had a higher pre-test likelihood of CAD (suspected vs no known or suspected CAD in DIAD, with about twice the prevalence of hypertension, dyslipidaemia and smoking), as well as a possibly more advanced stage of diabetes, as suggested by the higher insulin use (46\% vs $23 \%$ in DIAD), despite similar duration of diabetes (10 \pm 9 vs $9 \pm 8$ years in DIAD) [22].

Rather striking is the paucity of significant univariate or multivariate associations of reversible defects on MPS with clinical and laboratory data. This was also observed in DIAD, where only cardiac dysautonomia was significantly associated with reversible defects [23]. We found no association between silent ischaemia and the duration or type of diabetes, as previously reported [18]. Of interest, we observed more fixed defects in association with erectile dysfunction, a marker of autonomic neuropathy in men. This may be explained by the known close association of erectile dysfunction with diabetic autonomic neuropathy, vasculopathy and endothelial dysfunction. We found erectile dysfunction to be associated with peripheral neuropathy $(r=0.41, p<0.001)$, retinopathy $(r=0.20, p=0.02)$, vasculopathy $(r=0.28, p=0.001)$ and $\operatorname{smoking}(r=0.22, p=0.01)$, as reported previously [24]. Although erectile dysfunction can be related to medication, we found no association with $\beta$-blockers $(p=0.57)$ or ACE inhibitors in our study $(p=0.20)$. There was also no association with calcium antagonists, diuretics or lipid-lowering drugs (all $p>0.61$ ). Thus, a drug-induced aetiology was unlikely in our population. Finally, lower aspirin use was associated with fixed MPS defects. This might be of importance, as fixed defects have been demonstrated to have predictive value for cardiac death and myocardial infarction in diabetic patients [9].

\section{ST segment depression and chest pain during MPS}

The low prevalence of stress-induced ST segment depression during MPS is likely due to a referral bias (preexisting ECG abnormalities leading to the MPS referral) or to pharmacological testing (known to produce fewer changes on ECG [25]). The low prevalence of inducible chest pain during stress MPS has been described previously [3] and is known to have no influence on longterm prognosis [26]. Ejection fraction was diminished in the presence of reversible defects, while no difference was found with fixed defects $(p=0.37)$, based on data available in a subset of the population (Table 3 ).

\section{Prognosis and significance of silent ischaemia}

Few studies have investigated the significance and prognosis of silent ischaemia in diabetics, but a worse outcome is generally described for patients with silent ischaemia than for those without ischaemia [12]. It is known, however, that a normal MPS study in diabetic patientsas in non-diabetic patients-is correlated with a low rate of cardiac death and non-fatal myocardial infarction [8]. MPS was shown to be useful for risk stratification in asymptomatic diabetic patients without known CAD (2\%/year hard event rate for normal MPS vs $9 \% / y e a r$ for abnormal MPS) [21]. In symptomatic diabetic patients referred for MPS with suspected or known CAD, the presence and extent of stress abnormalities on MPS were shown to predict cardiac events [9].

\section{Comparison with available angiographic data}

In our study, 20 patients underwent coronary angiography within 60 days of MPS; 11 of these studies were in patients with reversible defects, suggestive of ischaemia. Of great interest, significant stenosis $(\geq 70 \%$ in the left anterior descending, left circumflex or right coronary artery or $\geq 50 \%$ in the left main coronary artery) was found in only $64 \%$ (7/11) of the angiographic studies, while the rest showed non-obstructive diffuse atherosclerotic disease (stenosis $<50 \%$ ). In the literature, several studies have reported that about $50 \%$ of diabetic patients with silent myocardial ischaemia exhibit no significant coronary stenosis on angiography $[10,27,28]$. This contrasts with the generally higher positive predictive value ob- 
tained in non-diabetic patients. Rather than MPS being false positive in such cases, some of these patients may have myocardial perfusion abnormalities reflecting a reduced capacity to increase blood flow due to increased epicardial resistance that is related to minimal or diffuse atherosclerosis and/or microvascular dysfunction, as previously suggested [29-33]. Microvascular dysfunction, such as evidenced during exposure to cold, has been described in diabetic patients and may explain MPS abnormalities in patients without significant epicardial coronary stenosis [34]. Microvascular dysfunction is of predictive value for long-term cardiovascular events in type 2 diabetic patients with normal coronary arteries [35]. Importantly, the association of abnormal coronary vasomotion with reversible perfusion defects has demonstrated prognostic value (higher risk of subsequent cardiovascular events) $[36,37]$. Interestingly, in a study of asymptomatic diabetic patients, Cosson et al. described that significant coronary stenosis $(\geq 70 \%)$ was found in only $47 \%$ of patients with silent ischaemia by SPECT and that such "silent" coronary stenosis was associated with a worse cardiovascular outcome [28].

\section{Comparison with screening criteria}

When retrospectively applying the ADA criteria for screening asymptomatic diabetic patients to our group without chest pain, we found that only 63\% (47/75) would have met the guideline requirements for screening. Their SSS, SDS, SRS and prevalence of reversible defects (all $p>0.18$ ) were similar to those in the $37 \%$ $(28 / 75)$ of patients not meeting the criteria. In contrast, the prevalence of fixed defects in patients not meeting the screening criteria, at $29 \%(8 / 28)$, was significantly higher than the corresponding rate of $8.5 \%(4 / 47)$ in patients qualifying for screening $(p=0.05)$. Although retrospective, this comparison reveals the existence of a group of asymptomatic diabetic patients with suspected CAD who would not normally be screened based on the ADA criteria, yet who have a similar prevalence of reversible defects and perhaps a higher prevalence of fixed defects in comparison with patients meeting the ADA criteria. Taken together, these findings indicate that the current screening guidelines may not be optimal and emphasise the need for prospective studies (such as DIAD) to establish evidence-based criteria.

\section{Clinical implications}

The diagnostic and prognostic value of SPECT MPS has been established in diabetic patients with and without CAD. However, evidence-based criteria for screening diabetic patients using MPS are still lacking, and the outcome of the ongoing DIAD trial will help to define such criteria and stratify clinical risk. Until then, cardiac testing has been recommended not only in diabetic patients with symptoms indicating the presence of CAD but also in patients with possible anginal equivalents and in asymptomatic patients (guidelines of the Association de Langue Française pour l'Étude du Diabète et des Maladies Métaboliques [5] and the American Diabetes Association (ADA)-American College of Cardiology [6]).

\section{Study limitations}

In this study, the patients referred for MPS represented a group with an intermediate likelihood of CAD, as patients with a higher likelihood (such as those with typical anginal pain and clear exercise-induced ECG changes) would most likely have been sent directly to coronary angiography while patients with a lower likelihood would not have been referred for MPS. This restricts the validity of our results to a similar clinical setting of unselected diabetic patients referred to nuclear medicine for MPS; certainly, our findings cannot be extended to the general diabetic population. We did not have systematic information on autonomic dysfunction and erectile dysfunction was self-reported; a more objective evaluation would be required by the use of an appropriately validated questionnaire, the inclusion of which would be worthwhile in any future prospective study. The association of lower aspirin use with fixed defects on MPS awaits confirmation in larger samples. Finally, functional data on ejection fraction are given solely for informational purposes, as they were available in only a subset of the population $(65 \%)$.

\section{Conclusion}

In diabetic patients without known CAD referred for MPS in the clinical setting, there was a high overall prevalence of abnormal SPECT (37\%) and reversible defects $(30 \%)$, indicative of stress-induced ischaemia. Patients without a history of chest pain had a similar prevalence $(31 \%)$ of reversible defects as patients with a history of chest pain. MPS could identify patients with a potentially increased risk of cardiovascular events.

Acknowledgements. We would like to acknowledge the help of our nuclear medicine technician staff and of our physicians in performing the clinical studies (Drs. A. Boubaker, M.-F. Bézy, N. Besseghir, V. Vaclavik, M. Piller, G. Storto, G. Barghouth, J.-P. Willi, C. Müller, C. Antonescu, F. Bonvin and M. Zwimpfer). We are also greatly indebted to Prof. H.R. Schelbert, Drs. T.H. Schindler and X.-L. Zhang (Department of Molecular and Medical Pharmacology, David Geffen School of Medicine at UCLA, USA) for critical comments and suggestions. 


\section{References}

1. King H, Aubert RE, Herman WH. Global burden of diabetes, 1995-2025: prevalence, numerical estimates, and projections. Diabetes Care 1998;21:1414-31.

2. Stamler J, Vaccaro O, Neaton JD, Wentworth D. Diabetes, other risk factors, and 12-yr cardiovascular mortality for men screened in the multiple risk factor intervention trial. Diabetes Care 1993;16:434-44.

3. Klein J, Chao SY, Berman DS, Rozanski A. Is 'silent' myocardial ischemia really as severe as symptomatic ischemia? The analytical effect of patient selection biases. Circulation 1994;89:1958-66.

4. Fowler PB. The UK prospective diabetes study. Lancet 1998;352:1933; author reply 1934.

5. Passa P, Drouin P, Issa-Sayegh M, Blasco A, Masquet C, Monassier JP, Paillole C. Coronary disease and diabetes. Diabetes Metab 1995;21:446-51.

6. Consensus development conference on the diagnosis of coronary heart disease in people with diabetes: 10-11 February 1998, Miami, Florida. American Diabetes Association. Diabetes Care 1998;21:1551-9.

7. Underwood SR, Anagnostopoulos C, Cerqueira M, Ell PJ, Flint EJ, Harbinson M, et al. Myocardial perfusion scintigraphy: the evidence. A consensus conference organised by the British Cardiac Society, the British Nuclear Cardiology Society and the British Nuclear Medicine Society, endorsed by the Royal College of Physicians of London and the Royal College of Radiologists. Eur J Nucl Med Mol Imaging 2004; 31:261-91. DOI 10.1007/s00259-003-1344-5.

8. Kang X, Berman DS, Lewin HC, Cohen I, Friedman JD, Germano G, et al. Incremental prognostic value of myocardial perfusion single photon emission computed tomography in patients with diabetes mellitus. Am Heart J 1999;138:102532.

9. Giri S, Shaw LJ, Murthy DR, Travin MI, Miller DD, Hachamovitch R, et al. Impact of diabetes on the risk stratification using stress single-photon emission computed tomography myocardial perfusion imaging in patients with symptoms suggestive of coronary artery disease. Circulation 2002; 105:32-40.

10. Koistinen MJ. Prevalence of asymptomatic myocardial ischaemia in diabetic subjects. Br Med J 1990;301:92-5.

11. Milan Study on Atherosclerosis and Diabetes (MiSAD) Group. Prevalence of unrecognized silent myocardial ischemia and its association with atherosclerotic risk factors in noninsulin-dependent diabetes mellitus. Am J Cardiol 1997; 79:134-9. DOI 10.1016/S0002-9149(96)00699-6.

12. Weiner DA, Ryan TJ, Parsons L, Fisher LD, Chaitman BR, Sheffield LT, Tristani FE. Significance of silent myocardial ischemia during exercise testing in patients with diabetes mellitus: a report from the Coronary Artery Surgery Study (CASS) registry. Am J Cardiol 1991;68:729-34.

13. Wackers FJT, Young LH, Inzucchi SE, Chyun DA, Davey JA. Detection of ischemia in asymptomatic diabetics: preliminary results of the DIAD study. J Am Coll Cardiol 2003;41:409a.

14. Rose G, Blackburn H, Gillum RF, Prineas RJ. Cardiovascular survey methods. 2nd edn. Geneva: WHO; 1982.

15. Imaging guidelines for nuclear cardiology procedures, part 2. American Society of Nuclear Cardiology. J Nucl Cardiol 1999;6:G47-84.

16. Berman DS, Kiat H, Friedman JD, Wang FP, van Train K, Matzer L, et al. Separate acquisition rest thallium-201/stress technetium-99m sestamibi dual-isotope myocardial perfusion single-photon emission computed tomography: a clinical validation study. J Am Coll Cardiol 1993;22:1455-64.

17. Hachamovitch R, Berman DS, Shaw LJ, Kiat H, Cohen I, Cabico JA, et al. Incremental prognostic value of myocardial perfusion single photon emission computed tomography for the prediction of cardiac death: differential stratification for risk of cardiac death and myocardial infarction. Circulation 1998;97:535-43.

18. Janand-Delenne B, Savin B, Habib G, Bory M, Vague P, Lassmann-Vague V. Silent myocardial ischemia in patients with diabetes: who to screen. Diabetes Care 1999;22:1396400.

19. Vanzetto G, Halimi S, Hammoud T, Fagret D, Benhamou PY, Cordonnier D, et al. Prediction of cardiovascular events in clinically selected high-risk NIDDM patients. Prognostic value of exercise stress test and thallium-201 single-photon emission computed tomography. Diabetes Care 1999;22:19-26.

20. Inoguchi T, Yamashita T, Umeda F, Mihara H, Nakagaki O, Takada K, et al. High incidence of silent myocardial ischemia in elderly patients with non insulin-dependent diabetes mellitus. Diabetes Res Clin Pract 2000;47:37-44. DOI 10.1016/S0168-8227(99)00102-3.

21. De Lorenzo A, Lima RSL, Siqueira-Filho AG, Pantoja MR. Prevalence and prognostic value of perfusion defects detected by stress technetium-99m sestamibi myocardial perfusion single-photon emission computed tomography in asymptomatic patients with diabetes mellitus and no known coronary artery disease. Am J Cardiol 2002;90:827-32. DOI 10.1016/S00029149(02)02702-9.

22. Wackers F, Young L, Inzucchi S, Chyun D, Davey J. The prevalence of silent myocardial ischemia in asymptomatic patients with type 2 diabetes meltitus: results of the DIAD study. Diabetes 2003;52:A56.

23. Wackers FTJ, Young LH, Chyun DA, Davey JA, Inzucchi SE. Predictors of silent myocardial ischemia in patients with type 2 diabetes mellitus: results from the DIAD study. Diabetologia 2003;46:A23-4.

24. McCulloch DK, Campbell IW, Wu FC, Prescott RJ, Clarke BF. The prevalence of diabetic impotence. Diabetologia 1980; 18:279-83.

25. Zaret B, Beller GA. Nuclear cardiology—state of the art and future directions. 2nd edn. St. Louis: Mosby; 1999.

26. Pancholy SB, Schalet B, Kuhlmeier V, Cave V, Heo J, Iskandrian AS. Prognostic significance of silent ischemia. J Nucl Cardiol 1994;1:434-40.

27. Valensi P, Sachs RN, Lormeau B, Taupin JM, Ouzan J, Blasco A, et al. Silent myocardial ischaemia and left ventricle hypertrophy in diabetic patients. Diabetes Metab 1997;23:409-16.

28. Cosson E, Guimfack M, Paries J, Paycha F, Attali JR, Valensi P. Are silent coronary stenoses predictable in diabetic patients and predictive of cardiovascular events? Diabetes Metab 2003;29:470-6.

29. Zeiher AM, Krause T, Schachinger V, Minners J, Moser E. Impaired endothelium-dependent vasodilation of coronary resistance vessels is associated with exercise-induced myocardial ischemia. Circulation 1995;91:2345-52.

30. Schindler TH, Nitzsche E, Magosaki N, Brink I, Mix M, Olschewski M, et al. Regional myocardial perfusion defects during exercise, as assessed by three dimensional integration of morphology and function, in relation to abnormal endothelium dependent vasoreactivity of the coronary microcirculation. Heart 2003;89:517-26. 
31. Hasdai D, Gibbons RJ, Holmes Jr DR, Higano ST, Lerman A. Coronary endothelial dysfunction in humans is associated with myocardial perfusion defects. Circulation 1997;96:3390-5.

32. Blumenthal RS, Becker DM, Yanek LR, Aversano TR, Moy TF, Kral BG, Becker LC. Detecting occult coronary disease in a high-risk asymptomatic population. Circulation 2003;107:702-7. DOI 10.1161/01.CIR.0000048127.93169.88.

33. Verna E, Ceriani L, Giovanella L, Binaghi G, Garancini S. "False-positive" myocardial perfusion scintigraphy findings in patients with angiographically normal coronary arteries: insights from intravascular sonography studies. J Nucl Med 2000;41:1935-40.

34. Nitenberg A, Ledoux S, Valensi P, Sachs R, Attali JR, Antony I. Impairment of coronary microvascular dilation in response to cold pressor-induced sympathetic stimulation in type 2 dia- betic patients with abnormal stress thallium imaging. Diabetes 2001;50:1180-5.

35. Nitenberg A, Valensi P, Sachs R, Cosson E, Attali JR, Antony I. Prognostic value of epicardial coronary artery constriction to the cold pressor test in type 2 diabetic patients with angiographically normal coronary arteries and no other major coronary risk factors. Diabetes Care 2004;27:208-15.

36. Schachinger V, Britten MB, Zeiher AM. Prognostic impact of coronary vasodilator dysfunction on adverse long-term outcome of coronary heart disease. Circulation 2000; 101:1899-906.

37. Halcox JPJ, Schenke WH, Zalos G, Mincemoyer R, Prasad A, Waclawiw MA, et al. Prognostic value of coronary vascular endothelial dysfunction. Circulation 2002;106:653-8. DOI 10.1161/01.CIR.0000025404.78001.D8. 